Original Research Article

\title{
Beneficial effects of diacerein on adipokines and pro-inflammatory cytokines involved in diet-induced nonalcoholic steatohepatitis in rats
}

\author{
Omaima M. Abd Allah*
}

Department of Pharmacology and Therapeutics, Faculty of Medicine, Benha University, Benha, Egypt

Received: 13 March 2017 Accepted: 17 March 2017

*Correspondence to:

Omaima M. Abd Allah,

Email:

omiama_afify@yahoo.com

Copyright: (C) the author(s), publisher and licensee Medip Academy. This is an openaccess article distributed under the terms of the Creative Commons Attribution NonCommercial License, which permits unrestricted noncommercial use, distribution, and reproduction in any medium, provided the original work is properly cited.

\begin{abstract}
Background: Non-alcoholic steatohepatitis (NASH) is considered as a progressive liver disease, so effective therapies are needed to ameliorate hepatic steatosis, inflammation and fibrosis, and to prevent the progression to cirrhosis and hepatocellular carcinoma. Diacerein is an anti-inflammatory drug that inhibits the synthesis and activity of pro-inflammatory cytokines. The present study was designed to investigate the effect of diacerein on pro-inflammatory cytokines as well as adipokines involved in diet-induced NASH rat model.

Methods: Thirty-two adult male rats were divided into four groups: control, diacerein-treated, NASH-untreated and NASH+diacerein-treated groups. NASH was induced by feeding rats with high-fat and high-cholesterol diet for 12 weeks. Body weight, liver weight, fasting blood glucose and insulin levels for estimation of insulin resistance, blood lipids, alanine transaminase, and aspartate aminotransferase were evaluated. Serum levels of tumor necrosis factor- $\alpha$ (TNF- $\alpha)$, interleukin-1 $\beta$ (IL-1 $\beta$ ), interleukin-6 (IL-6), adiponectin, visfatin and leptin were also detected. Histopathological examination of liver sections was performed.

Results: Diacerein significantly reduced liver weight, fasting blood glucose, insulin level, transaminases and ameliorates insulin resistance with favourable effects on blood lipids. These results were accompanied with a significant reduction in serum levels of TNF- $\alpha$, IL-1 $\beta$, IL-6, and visfatin, while, adiponectin was significantly increased and leptin was insignificantly affected. Liver sections revealed that diacerein reduced steatosis and lobular inflammatory grades.

Conclusions: These data suggest that diacerein administration may have a potential usefulness in the prevention of NASH as a possible result of inhibition of pro-inflammatory cytokines and the beneficial effects on adipokines especially adiponectin and visfatin.
\end{abstract}

Keywords: Adipokines, Diacerein, Non-alcoholic steatohepatitis, Proinflammatory cytokines, Rat

\section{INTRODUCTION}

Nonalcoholic fatty liver disease (NAFLD) represents a range of disorders characterized by significant lipid deposition in the liver parenchyma. While simple steatosis may be clinically stable, non-alcoholic steatohepatitis (NASH) can be progressive, even to hepatocellular carcinoma. ${ }^{1}$ Despite extensive research over the past decades, the pathogenesis of NAFLD is not entirely understood, and treatment of the disease has not been fully defined. NAFLD was described as a "two hit model". The first hit is supposed to be the increase and accumulation of free fatty acids in hepatocytes and insulin resistance. The second step includes all mechanisms contributing to the production of proinflammatory cytokines and oxidative species, thereby enhances lipid peroxidation and inflammation. ${ }^{2}$

High fat diet and obesity are primarily involved in the up growth of NAFLD worldwide; it remains unclear why $10 \%$ of all people with fatty liver develop the 'inflammatory' phenotype (NASH). Inflammation is believed to be the driving force behind NASH and the progression to fibrosis and subsequent cirrhosis. Inflammatory mediators from adipose tissue (adipocytokines or adipokines) and the liver interact to mediate the pathogenesis of NAFLD, its progression, and in the emergence and regulation of insulin-resistance. ${ }^{3}$ It 
has been suggested that the development of steatohepatitis is a consequence of the balance between pro and anti-inflammatory effects of adipokines (e.g., adiponectin, resistin, visfatin and leptin). ${ }^{4}$ Proinflammatory cytokines such as interleukin (IL)-6, IL-1 $\beta$, and tumor necrosis factor (TNF)- $\alpha$ are involved in the pathogenesis of NAFLD and its progression to NASH, through their metabolic activity. ${ }^{5}$

Feeding rodents with an atherogenic diet, which contains high-fat components, has been shown to be a useful animal model provided us with the opportunity to access the pathophysiology of progressive NAFLD and NASH in humans.

Atherogenic diet which contains extra fat and cholesterol is prepared easily. Several studies found that high-fat and high-cholesterol diet induce liver steatosis, steatohepatitis, fibrosis, necrosis and cause excess oxidative stress in the liver. ${ }^{6,7}$ Besides, dyslipidaemia, insulin resistance, obesity and elevated serum aminotransferases accompany these liver changes. Dietary cholesterol constitutes a substantial risk factor in the headway of simple steatosis to NASH in rat models. ${ }^{8}$

Diacerein is an anthraquinone compound, of which the active metabolite is rhein, with anti-inflammatory properties that inhibit the synthesis and activity of proinflammatory cytokines, such as TNF- $\alpha$, IL-1 $\beta$ and IL-6. ${ }^{9}$ Diacerein is a compound with a long history but whose effects are still not fully understood. Recently, knowledge about diacerein, showed that this drug improves insulin sensitivity, through the reversal of chronic subclinical inflammation. ${ }^{10}$ Diacerein has been shown to inhibit IL$1 \beta$ - induced activation of transcription factor, nuclear factor $\mathrm{NF}-\kappa \mathrm{B}$, which induces pro-inflammatory cytokine expression. $^{11}$

Amongst the numerous pathogenetic factors, many inflammatory processes are involved in the progression of NASH, therefore, we hypothesized that diacerein could revert steatohepatitis, including hepatic inflammation through its anti-inflammatory properties. Therefore, we investigated the effect of diacerein on proinflammatory cytokines as well as adipokines involved in high-fat and high-cholesterol diet-induced NASH rat model.

\section{METHODS}

\section{Drugs}

Diacerein (DIA) powder was obtained from Eva Pharma Company, Egypt and was suspended in $0.5 \%$ carboxymethyl cellulose (CMC). Cholesterol powder was purchased from El-Gomhouria Company, Egypt. All other chemicals were of highest grade commercially available.

\section{Animals}

A total of thirty-two adult male Sprague-Dawley rats, weighing 150-180 $\mathrm{g}$ at the start of the experiment, were purchased from Helwan farm (Holding Company for Biological Products and Vaccines, VACSERA, Egypt). The animals were housed (four per cage) in the animal facility of Pharmacology Department, Faculty of Medicine, Benha University, Egypt for one week before the onset of the experiment for acclimatization. The animals were maintained under good hygienic and standard laboratory conditions ( $12 \mathrm{~h}$ light/ dark cycles at $25 \pm 2^{\circ} \mathrm{C}$ ), fed ad libitum and allowed for free water supply. All animal treatments adhered strictly to institutional and international ethical guidelines of the care and use of laboratory animals. The experimental protocol was approved by ethical committee (Faculty of medicine, Benha University, Egypt).

\section{Experimental design}

The experimental animals were divided into four groups, each group consisting of eight rats as follows: control group, diacerein-treated group, NASH-untreated group and NASH+ diacerein-treated group. The rats of control group fed with standard diet and they were administered $1 \mathrm{ml} / \mathrm{rat} 0.5 \% \mathrm{CMC}$ orally as a vehicle without any treatment for 12 weeks. Diacerein-treated group fed with standard diet and they were received diacerein once daily $(15 \mathrm{mg} / \mathrm{kg}$, orally) suspended in $1 \mathrm{ml} /$ rat $0.5 \% \mathrm{CMC}$ for 12 weeks. NASH-untreated group fed with high-fat and high-cholesterol diet (HFHC diet consist of standard diet plus $10 \%$ animal fat, $2 \%$ cholesterol, and 5\% corn oil) (Wang et al) for induction of NASH, concomitantly they were administered $1 \mathrm{ml} / \mathrm{rat} 0.5 \% \mathrm{CMC}$ orally as a vehicle without any treatment for 12 weeks. NASH+ diacereintreated group fed with HFHC diet, concomitantly they were received diacerein once daily $(15 \mathrm{mg} / \mathrm{kg}$, orally) suspended in $1 \mathrm{ml} /$ rat $0.5 \% \mathrm{CMC}$ for 12 weeks. The dose of diacerein was selected on the basis of previous experimental studies in rats. ${ }^{12}$ The diacerein-treated group was performed to explore any toxic effect of the drug on the liver. Before each administration, a fresh solution was prepared in $0.5 \% \mathrm{CMC}$ to obtain the necessary drug concentration in $1 \mathrm{ml}$.

At the end of 12 weeks, animals were weighed, 24 hours after the last treatment or vehicle administration and subsequent to 12 hours fasting (for estimation of fasting blood glucose and insulin levels and to minimize feedinginduced variations in lipid profile), animals were anaesthetized with diethyl ether and then sacrificed by cervical decapitation. Blood samples were collected by cardiac puncture for serum separation and biochemical analysis. Blood samples were allowed to clot at room temperature then serum was separated by centrifugation of blood at $3000 \mathrm{rpm}$ for $15 \mathrm{~min}$ and the sera were stored at $-20^{\circ} \mathrm{C}$ until assayed. Livers were immediately removed, rinsed in ice-cold saline and weighed for calculation of liver weight index $(\%)$ as liver weight/body weight $\times 100$. 
Liver samples from different liver lobes were fixed in $10 \%$ formalin for histpathological analysis.

\section{Biochemical analysis}

\section{Assessment of fasting blood glucose and insulin level}

Fasting blood glucose level was determined by the glucose oxidase method.13 Serum insulin level was determined with the enzyme-linked immunosorbent assay (ELISA) method using a rat insulin kit (Sigma-Aldrich, Germany). Insulin resistance was calculated using Homeostasis Model Assessment of Insulin Resistance (HOMA-IR) test on the basis of fasting insulin (I) (in $\mu \mathrm{U} / \mathrm{mL}$ ) and glucose $(\mathrm{G})$ levels (in $\mathrm{mg} / \mathrm{dl}$ ) and according to the formula HOMA-IR= I x G/405.14

\section{Liver function tests}

Serum levels of alanine aminotransferase (ALT) and aspartate aminotransferase (AST) were assessed using colorimetric enzymatic kits (Bio Diagnostic, Dokki, Giza, Egypt) according to the manufacturer's instructions.

\section{Assessment of blood lipids}

Serum levels of total cholesterol (TC), triglyceride (TG) and high- density lipoprotein-cholesterol (HDL-C) were determined using colorimetric enzymatic kits (Bio Diagnostic, Dokki, Giza, Egypt) according to the manufacturer's instructions. Low-density lipoprotein cholesterol (LDL-C) was calculated using the Friedewald formula.15 Rat free fatty acid (FFA) enzyme-linked immunosorbent assay (ELISA) kits (Abcam, UK) were used to assess serum level of free fatty acids (FFAs).

Assessment of Serum pro-inflammatory cytokines and adipokines. Serum levels of TNF- $\alpha$, IL-1 $\beta$, and IL- 6 were measured by Rat Quantikine ELISA kits ( $\mathrm{R}$ and $\mathrm{D}$ Systems, Minneapolis, MN, USA) which were purchased from Clinilab, Cairo, Egypt. All procedures were performed according to the manufacturer's instructions. Serum adiponectin and leptin were assessed using specific rat ELISA kits (Biovendor, Germany) according to the manufacturer's instructions. The kits were purchased from GAMMA Trade Co. Cairo, Egypt. Rat visfatin ELISA Kits (MyBioSource, USA), purchased from Science and Technology Center, Giza, Egypt, was used for assessment of serum visfatin level.

\section{Histopathological analysis}

Liver tissues were collected from all dissected animals; livers were fixed in $10 \%$ formalin and embedded in paraffin. The sections were cut $(6 \mu \mathrm{m})$ and stained with hematoxylin and eosin (H\&E). All samples were evaluated by an experienced pathologist who was blinded to the experiment. Histopathological changes were assessed and photographed under light microscope (Leica DM 500 with ICC50 HD camera). All fields in each section were examined for grading of steatosis, inflammation, and ballooning degeneration according to the criteria described by Brunt et al. ${ }^{16}$

The severity of steatosis was graded as the percentage of parenchymal cells containing macrovesicular fat as follows: $0=$ less than $5 \%$ of hepatocytes containing fat, 1 $=$ less than $33 \%$ of hepatocytes containing fat, $2=33-$ $66 \%$ of hepatocytes containing fat, and $3=$ more than $66 \%$ of hepatocytes containing fat. Hepatic lobular inflammation was scored from 0 to 3 based on counting the inflammatory foci per 20 high-power fields $(20 \times)$ with a $20 \times$ ocular $(0=$ no inflammation, $1=1$ to $2 / 20 x$; $2=$ up to $4 / 20 \times ; 3=>4 / 20 \times$ ). The presence of ballooning degeneration which is the key character used to distinguish the developed NASH from the less progressive forms of NAFLD was graded from 0 to 2: $0=$ no ballooning cell, 1 = few balloon hepatocytes, and $2=$ many balloon hepatocytes.

\section{Statistical analysis}

Data are expressed as mean \pm standard error of the mean (SE). Statistical analysis was performed using one way analysis of variance (ANOVA) followed by Tukey's post Hoc test using the Statistical Program of Social Sciences (SPSS) for windows (version 16; SPSS, Chicago, IL, USA). Significant differences between experimental groups were determined at $\mathrm{P}<0.05$.

\section{RESULTS}

There were no statistically significant changes in all measured biochemical parameters between diacereintreated groups compared with the control group $(\mathrm{p}>0.05)$.

\section{Effect of diacerein on body weight, liver weight and liver weight index}

At the end of the $12^{\text {th }}$ week, the livers of NASH-untreated rats were enlarged with an irregular, partially nodular surface. Liver weight was significantly $(\mathrm{p}<0.05)$ increased compared to control group. Treatment of NASH rats with diacerein resulted in significant $(\mathrm{p}<0.05)$ decrease in liver weight with significant $(\mathrm{p}<0.05)$ decrease in liver weight index compared to NASH-untreated group. However, diacerein treatment did not affect body weight as it produce insignificant $(\mathrm{p}>0.05)$ decrease in body weight compared to NASH-untreated group (Table 1).

\section{Effect of diacerein on fasting blood glucose, insulin level and insulin resistance}

In NASH-untreated group, HFHC diet significantly caused insulin resistance indicated by significant ( $p$ $<0.05$ ) increased fasting glucose and insulin levels as well as by increased HOMA-IR index compared to control group. In $\mathrm{NASH}+$ diacerein treated rats, fasting blood glucose and insulin levels were reduced significantly ( $p$ $<0.05$ ), diacerein was effective in trimming down insulin 
resistance as evidenced by significant $(\mathrm{p}<0.05)$ decrease in HOMA-IR index compared to NASH-untreated group (Table 2).

Table 1: Effects of diacerein (DIA, $15 \mathrm{mg} / \mathrm{kg}$, orally for 12 weeks) on body weight, liver weight and liver weight index in rats fed with high-fat and highcholesterol diet.

\begin{tabular}{|c|c|c|c|}
\hline & $\begin{array}{l}\text { Body } \\
\text { weight (g) }\end{array}$ & $\begin{array}{l}\text { Liver } \\
\text { weight (g) }\end{array}$ & $\begin{array}{l}\text { Liver } \\
\text { weight } \\
\text { index } \%\end{array}$ \\
\hline $\begin{array}{l}\text { Control } \\
\text { group }\end{array}$ & $313.6 \pm 12.4$ & $8.9 \pm 0.4$ & $2.93 \pm 0.2$ \\
\hline $\begin{array}{l}\text { DIA-treated } \\
\text { group }\end{array}$ & $322.5 \pm 12.6$ & $9.2 \pm 0.5$ & $2.81 \pm 0.2$ \\
\hline $\begin{array}{l}\text { NASH- } \\
\text { untreated } \\
\text { group }\end{array}$ & $438.2 \pm 23.5^{\mathrm{ab}}$ & $14.6 \pm 1.3^{\mathrm{ab}}$ & $3.89 \pm 0.6^{\mathrm{ab}}$ \\
\hline $\begin{array}{l}\text { NASH+DIA } \\
\text { treated group }\end{array}$ & $429.2 \pm 14.9^{\mathrm{ab}}$ & $10.8 \pm 0.9^{c}$ & $2.46 \pm 0.3^{\mathrm{c}}$ \\
\hline
\end{tabular}

Values are expressed as mean \pm SE ( $\mathrm{n}=8$ rats)

a: $\mathrm{P}<0.05$ significant difference when compared to control group.

b: $\mathrm{P}<0.05$ significant difference when compared to diacereintreated group.

c: $\mathrm{P}<0.05$ significant difference when compared to NASHuntreated group.

Table 2: Effects of diacerein (DIA, $15 \mathrm{mg} / \mathrm{kg}$, orally for 12 weeks) on fasting blood glucose, insulin level and Homeostasis Model Assessment of Insulin

Resistance (HOMA-IR index) in rats fed with high-fat and high-cholesterol diet.

\begin{tabular}{|llll|}
\hline & $\begin{array}{l}\text { FBG } \\
(\mathrm{mg} / \mathrm{dl})\end{array}$ & $\begin{array}{l}\text { Insulin } \\
(\mu \mathrm{U} / \mathrm{ml})\end{array}$ & $\begin{array}{l}\text { HOMA-IR } \\
\text { index }\end{array}$ \\
\hline $\begin{array}{l}\text { Control } \\
\text { group }\end{array}$ & $74.5 \pm 1.6$ & $10.8 \pm 1.2$ & $2.3 \pm 0.4$ \\
\hline $\begin{array}{l}\text { DIA-treated } \\
\text { group }\end{array}$ & $78.6 \pm 1.9$ & $11.4 \pm 1.3$ & $2.4 \pm 0.3$ \\
\hline $\begin{array}{l}\text { NASH- } \\
\text { untreated } \\
\text { group }\end{array}$ & $197.8 \pm 2.4^{\mathrm{ab}}$ & $26.4 \pm 1.9^{\mathrm{ab}}$ & $5.6 \pm 0.5^{\mathrm{ab}}$ \\
\hline $\begin{array}{l}\text { NASH+DI } \\
\text { A-treated } \\
\text { group }\end{array}$ & $156.2 \pm 1.8^{\mathrm{abc}}$ & $16.9 \pm 1.2^{\mathrm{abc}}$ & $3.2 \pm 0.4^{\mathrm{abc}}$ \\
\hline
\end{tabular}

Values are expressed as mean \pm SE $(n=8$ rats)

a: $\mathrm{P}<0.05$ significant difference when compared to control group.

b: $\mathrm{P}<0.05$ significant difference when compared to diacereintreated group.

c: $\mathrm{P}<0.05$ significant difference when compared to NASHuntreated group.

\section{Effect of diacerein on functional liver parameters}

The levels of serum ALT and AST were significantly $(p<0.05)$ increased with the consumption of HFHC diet. Compared with rats in NASH-untreated group, the levels of ALT and AST were significantly $(\mathrm{p}<0.05)$ declined in rats of NASH+ diacerein-treated group (Table 3 ).

Table 3: Effects of diacerein (DIA, $15 \mathrm{mg} / \mathrm{kg}$, orally for 12 weeks) on liver function parameters in rats fed with high-fat and high-cholesterol diet.

\begin{tabular}{|lll|}
\hline & ALT (U/L) & AST (U/L) \\
\hline Control group & $41.4 \pm 2.2$ & $33.6 \pm 1.2$ \\
\hline DIA-treated group & $44.5 \pm 2.1$ & $32.4 \pm 1.4$ \\
\hline NASH-untreated group & $128.3 \pm 5.7^{\mathrm{ab}}$ & $93.8 \pm 3.4^{\mathrm{ab}}$ \\
\hline NASH+DIA-treated group & $89.5 \pm 3.6^{\mathrm{abc}}$ & $46.7 \pm 2.6^{\mathrm{abc}}$ \\
\hline
\end{tabular}

Values are expressed as mean $\pm \mathrm{SE}(\mathrm{n}=8$ rats)

a: $\mathrm{P}<0.05$ significant difference when compared to control group.

b: $\mathrm{P}<0.05$ significant difference when compared to diacereintreated group.

c: $\mathrm{P}<0.05$ significant difference when compared to NASHuntreated group.

\section{Effect of diacerein on serum lipid profile}

NASH-untreated rats had significantly $(\mathrm{p}<0.05)$ higher serum cholesterol, triglyceride, LDL-C and free fatty acids levels compared to control group.

While, rats of NASH+ diacerein-treated group showed significant $(\mathrm{p}<0.05)$ reduction in serum cholesterol, triglyceride, LDL-C and free fatty acids levels compared to NASH-untreated group. However, these parameters remain significantly $(\mathrm{p}<0.05)$ higher in NASH+ diacereintreated group compared to control group (Table 4).

On the other hand, the serum level of HDL-C was significantly $(p<0.05)$ decreased in NASH-untreated group compared to control rats.

In NASH+ diacerein-treated group a significant elevation $(p<0.05)$ in HDL-C level was detected compared to $\mathrm{NASH}$-untreated rats.

However, its level remain significantly $(\mathrm{p}<0.05)$ lower in $\mathrm{NASH}+$ diacerein-treated group compared to control group (Table 4).

\section{Effect of diacerein on serum pro-inflammatory cytokines and adipokines}

The serum level of TNF- $\alpha$, IL- 6 and IL-1 $\beta$ were significantly $(\mathrm{p}<0.05)$ increased in NASH-untreated group compared with control group. NASH+ diacereintreated rats had significantly $(\mathrm{p}<0.05)$ reduced serum levels of these pro-inflammatory cytokines compared with NASH-untreated group.

Regarding these parameters, there was insignificant $(\mathrm{p}>0.05)$ difference between $\mathrm{NASH}+$ diacerein-treated and control groups (Figures 1, 2, 3). 
Table 4: Effects of diacerein (DIA, $15 \mathrm{mg} / \mathrm{kg}$, orally for 12 weeks) on serum lipid metabolism parameters in rats fed with high-fat and high-cholesterol diet.

\begin{tabular}{|lllll|l|}
\hline & TC $(\mathrm{mg} / \mathrm{dL})$ & TG $(\mathrm{mg} / \mathrm{dL})$ & HDL-C $(\mathrm{mg} / \mathrm{dL})$ & LDL-C $(\mathrm{mg} / \mathrm{dL})$ & FFA $(\mathrm{mmol} / \mathrm{L})$ \\
\hline Control group & $96.8 \pm 1.9$ & $103.5 \pm 1.2$ & $43.8 \pm 1.3$ & $26.8 \pm 0.8$ & $0.59 \pm 0.09$ \\
\hline DIA-treated group & $93.6 \pm 1.5$ & $98.4 \pm 1.3$ & $42.9 \pm 1.1$ & $25.4 \pm 0.6$ & $0.63 \pm 0.07$ \\
\hline NASH-untreated group & $245.8 \pm 4.2^{\mathrm{ab}}$ & $149.2 \pm 3.2^{\mathrm{ab}}$ & $34.2 \pm 0.7^{\mathrm{ab}}$ & $122.7 \pm 2.1^{\mathrm{ab}}$ & $1.82 \pm 0.14^{\mathrm{ab}}$ \\
\hline NASH+DIA- treated group & $147.5 \pm 3.1^{\mathrm{abc}}$ & $124.8 \pm 2.1^{\mathrm{abc}}$ & $36.6 \pm 0.9^{\mathrm{abc}}$ & $79.3 \pm 1.4^{\mathrm{abc}}$ & $1.46 \pm 0.09^{\mathrm{abc}}$ \\
\hline
\end{tabular}

Total cholesterol (TC), triglyceride (TG), high- density lipoprotein-cholesterol (HDL-C), low-density lipoprotein cholesterol (LDL-C), free fatty acids (FFAs)

Values are expressed as mean $\pm \mathrm{SE}(\mathrm{n}=8$ rats)

a: $\mathrm{P}<0.05$ significant difference when compared to control group

b: $\mathrm{P}<0.05$ significant difference when compared to diacerein-treated group

c: $\mathrm{P}<0.05$ significant difference when compared to NASH-untreated group

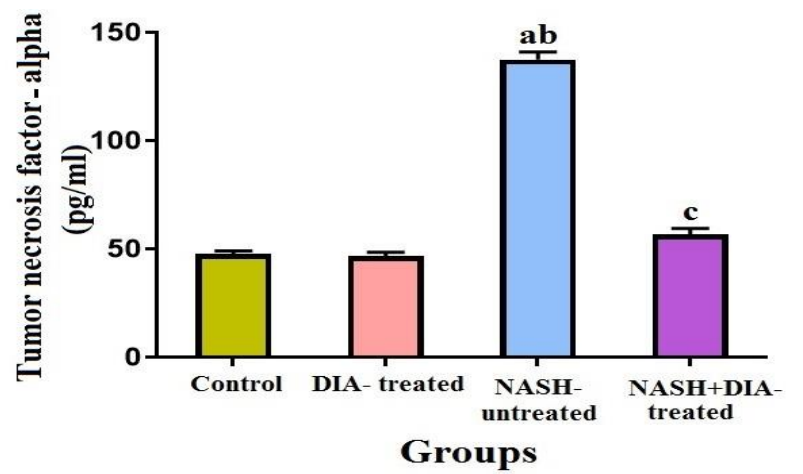

a: $P<0.05$ significant difference when compared to control group.

b: $\mathrm{P}<0.05$ significant difference when compared to diacereintreated group.

c: $\mathrm{P}<0.05$ significant difference when compared to NASHuntreated group

Figure 1: Effects of diacerein (DIA, $15 \mathrm{mg} / \mathrm{kg}$, orally for 12 weeks) on serum level of tumor necrosis factor$\alpha(\mathrm{TNF}-\alpha)$ in rats fed with high-fat and high cholesterol diet.

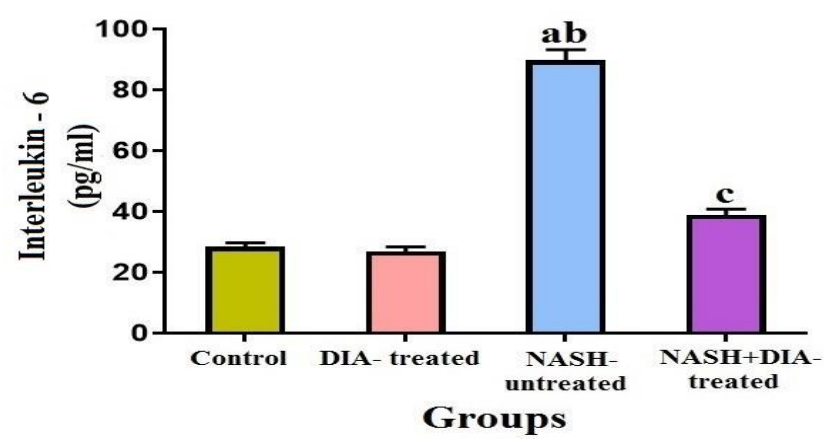

a: $\mathrm{P}<0.05$ significant difference when compared to control group.

b: $\mathrm{P}<0.05$ significant difference when compared to diacereintreated group.

c: $\mathrm{P}<0.05$ significant difference when compared to NASHuntreated group

Figure 2: Effects of diacerein (DIA, $15 \mathrm{mg} / \mathrm{kg}$, orally for 12 weeks) on serum level of interleukin-6 (IL-6) in rats fed with high-fat and high-cholesterol diet.

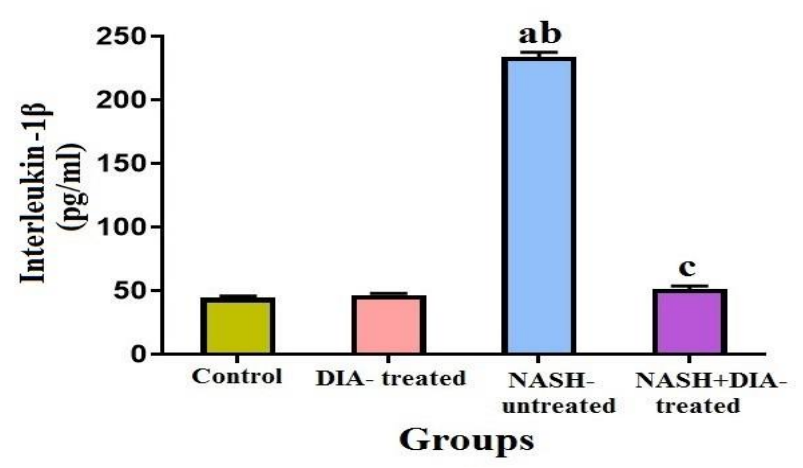

a $\mathrm{P}<0.05$ significant difference when compared to control group.

b $\mathrm{P}<0.05$ significant difference when compared to diacereintreated group.

c $\mathrm{P}<0.05$ significant difference when compared to NASHuntreated group

Figure 3: Effects of diacerein (DIA, $15 \mathrm{mg} / \mathrm{kg}$, orally

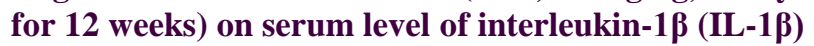
in rats fed with high-fat and high-cholesterol diet.

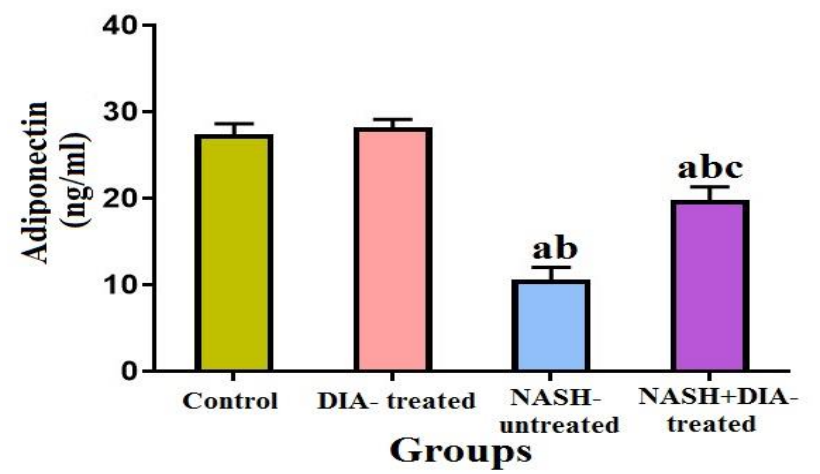

a: $\mathrm{P}<0.05$ significant difference when compared to control group.

b: $\mathrm{P}<0.05$ significant difference when compared to diacereintreated group.

c: $\mathrm{P}<0.05$ significant difference when compared to NASHuntreated group

Figure 4: Effects of diacerein (DIA, $15 \mathrm{mg} / \mathrm{kg}$, orally for 12 weeks) on serum level of adiponectin in rats fed with high-fat and high-cholesterol diet. 
On the other hand, adiponectin level significantly $(\mathrm{p}<0.05)$ declined in NASH-untreated group compared with control group. In NASH+ diacerein-treated group, a significant $(\mathrm{p}<0.05)$ increase in serum adiponectin was detected compared with the NASH-untreated group (Figure 4).

HFHC diet induced significant $(\mathrm{p}<0.05)$ increase in serum level of leptin and visfatin compared to control rats. In NASH+ diacerein-treated group, serum level of visfatin was significantly $(\mathrm{p}<0.05)$ reduced compared to NASH-untreated group (Figure 5).

While, diacerein decreased serum level of leptin insignificantly $(\mathrm{p}>0.05)$ (Figure 6).

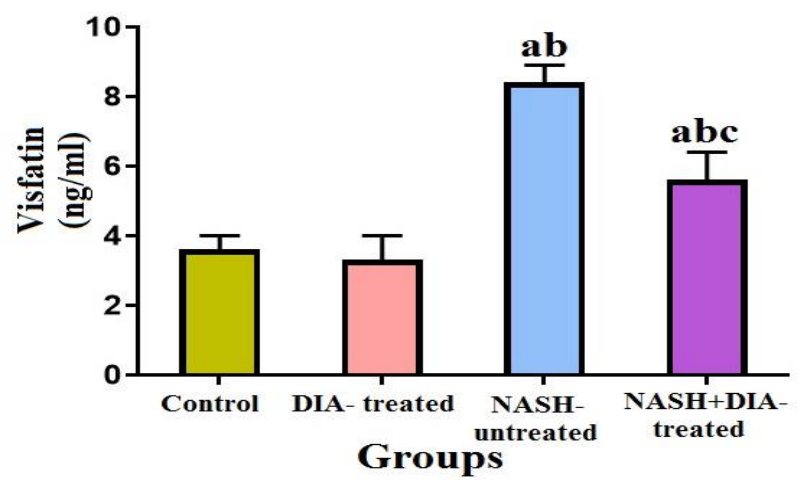

a: $\mathrm{P}<0.05$ significant difference when compared to control group.

b: $\mathrm{P}<0.05$ significant difference when compared to diacereintreated group.

c: $\mathrm{P}<0.05$ significant difference when compared to NASHuntreated group

Figure 5: Effects of diacerein (DIA, $15 \mathrm{mg} / \mathrm{kg}$, orally for 12 weeks) on serum level of visfatin in rats fed with high-fat and high-cholesterol diet.

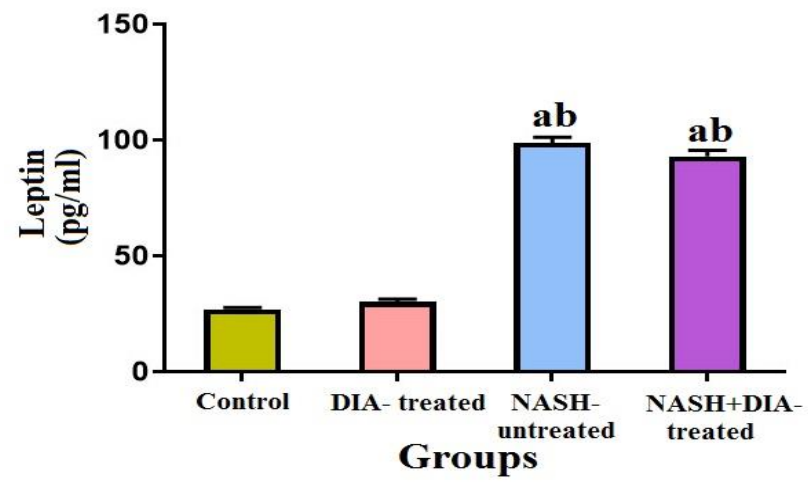

a: $\mathrm{P}<0.05$ significant difference when compared to control group.

b: $\mathrm{P}<0.05$ significant difference when compared to diacereintreated group.

c: $\mathrm{P}<0.05$ significant difference when compared to NASHuntreated group

Figure 6: Effects of diacerein (DIA, 15mg/kg, orally for 12 weeks) on serum level of leptin in rats fed with high-fat and high-cholesterol diet.
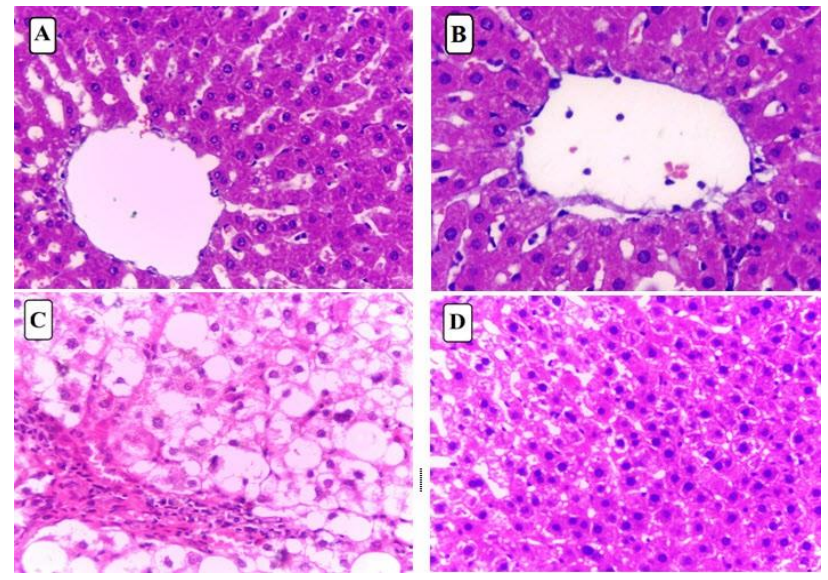

Figure 7: Representative photomicrographs of liver tissue sections (Hematoxylin and eosin $\times 400),(A, B)$ : Control and diacerein-treated groups fed a normal diet showing normal architecture with no histological abnormalities. (C): NASH-untreated group fed with high-fat and high-cholesterol diet for 12 weeks developed a high degree of steatosis (cytoplasmic vacuolation), ballooning degeneration and lobular inflammation (D): NASH+ diacerein-treated group showing apparently ameliorated steatosis, hepatocyte degeneration and reduced inflammatory cells infiltration.

Table 5: Effects of diacerein (DIA, $15 \mathrm{mg} / \mathrm{kg}$, orally for 12 weeks) on average histological grades of steatosis, inflammation and ballooning degeneration in livers of rats fed with high-fat and high-cholesterol diet.

\begin{tabular}{|c|c|c|c|}
\hline & Steatosis & $\begin{array}{l}\text { Lobular } \\
\text { inflammation }\end{array}$ & $\begin{array}{l}\text { Ballooning } \\
\text { degeneration }\end{array}$ \\
\hline $\begin{array}{l}\text { Control } \\
\text { group }\end{array}$ & $0.12 \pm 0.0$ & 0 & 0 \\
\hline $\begin{array}{l}\text { DIA- } \\
\text { treated } \\
\text { group }\end{array}$ & $0.12 \pm 0.0$ & 0 & 0 \\
\hline $\begin{array}{l}\text { NASH- } \\
\text { untreated } \\
\text { group }\end{array}$ & $3.24 \pm 0.5^{\mathrm{ab}}$ & $2.54 \pm 0.4^{\mathrm{ab}}$ & $1.37 \pm 0.2^{\mathrm{ab}}$ \\
\hline $\begin{array}{l}\text { NASH+DI } \\
\text { A-treated } \\
\text { group }\end{array}$ & $1.80 \pm 0.2^{\mathrm{abc}}$ & $0.97 \pm 0.1^{\mathrm{abc}}$ & $0.38 \pm 0.06^{\mathrm{abc}}$ \\
\hline \multicolumn{4}{|c|}{$\begin{array}{l}\text { Values are expressed as mean } \pm \mathrm{SE}(\mathrm{n}=8 \text { rats) } \\
\text { a: } \mathrm{P}<0.05 \text { significant difference when compared to control } \\
\text { group. } \\
\text { b: } \mathrm{P}<0.05 \text { significant difference when compared to diacerein- } \\
\text { treated group. } \\
\text { c: } \mathrm{P}<0.05 \text { significant difference when compared to NASH- } \\
\text { untreated group }\end{array}$} \\
\hline
\end{tabular}

\section{Effects of diacerein on liver histopathological parameters}

Microscopic examination of liver sections of control and diacerein-treated rats displayed normal liver architecture (Figure 7A, B). Rats of NASH-untreated group, fed HFHC diet for 12 weeks, not only developed a high 
degree of hepatic steatosis with severe cytoplasmic vacuoles and swelling of the hepatocytes (ballooning degeneration) but also exhibited more prominent inflammation, which was confirmed by morphological evidence of an abundance of polymorph nuclear inflammatory cells infiltration (Figure 7C), whereas, hepatocyte degeneration and the infiltration of inflammatory cells were significantly ( $p \quad<0.05)$ ameliorated in $\mathrm{NASH}+$ diacerein-treated rats (Figure 7D, Table 5).

\section{DISCUSSION}

NASH is considered as a progressive liver disease, so effective therapies are needed to ameliorate hepatic steatosis, inflammation and fibrosis, and to prevent the progression to cryptogenic cirrhosis and hepatocellular carcinoma. ${ }^{1}$ NASH-associated cirrhosis is currently the third most frequent reason for liver transplantation and is predicted to become the leading cause by $2020 .^{17}$

The HFHC diet rat model closely resembles the pathophysiology observed in human NASH. Dietary cholesterol and extra fats play a role in hepatic inflammation and progression of NASH. Hepatic macrophage (kupffer cells) becomes engorged with oxidized LDL which induces inflammatory cytokines secretion which acts on other hepatic cells and induce cell injury. Kupffer cells also secrete chemokines that recruit monocytes to the liver and amplify the inflammatory process. Controlling hepatic inflammation is an obvious target for NASH therapy. ${ }^{18}$

In the current study, by feeding rats a HFHC diet for 12 weeks, significant increase in body weight, liver weight and serum ALT and AST levels were detected suggesting the development of NASH model in rats which was confirmed by the histopathological findings such as steatosis, ballooning degeneration and lobular inflammation. These findings are in accordance with previous researches. ${ }^{6,7}$

The results of the present study also showed significant increase in serum levels of blood lipids, TNF- $\alpha$, IL- $1 \beta$, IL-6, leptin and visfatin with increased insulin resistance index (HOMA-IR) and decreased adiponectin level in NASH rats, thus confirming the role of the above factors on the pathogenesis of NASH.

The current study demonstrates the beneficial effects of an anti-inflammatory drug, diacerein, on insulin resistance, hepatic steatosis and inflammation in a rat experimental model of NASH. To our knowledge, the effects of diacerein on hepatic steatosis and NASH have not previously been investigated. The present findings suggest that modulation of the inflammatory response is a key factor in the progression of $\mathrm{NASH}$, in accordance with previous report supporting the potential clinical utility of a drug with anti-inflammatory effects in patients having predisposing factors of NAFLD and NASH. ${ }^{19}$
In the present study, the histopathological changes of the hepatic tissue in the HFHC fed group demonstrated hepatic cell injury, which led to the release of excessive amounts of intracellular hepatic transaminases into the serum. The structural distortion and the functional impairment of the hepatic cells by NASH were associated with increase in insulin level and high insulin resistance. These may be related to the excessive release of adipokines and FFAs from adipose tissue, which in turn, contribute to insulin resistance, increase blood glucose, and dyslipidemia. ${ }^{20}$ Diacerein treatment significantly decreased serum ALT and AST levels, these findings suggested that diacerein treatment ameliorated liver injury which was confirmed by reduced steatosis and lobular inflammatory grades in diacerein treated rats.

Our results revealed that diacerein decreases serum proinflammatory cytokine and adipokines levels, reduces fasting blood glucose and ameliorates insulin resistance. It was stated that TNF- $\alpha$, IL- 6 and IL-1 $\beta$ have been involved in apoptosis of pancreatic $\beta$-cells with the consequent hyperglycemia. In addition, inflammation of adipose tissue induce a systemic inflammation and insulin resistance. $^{21}$ Meanwhile, the anti-inflammatory properties of diacerein due to the decrease of some cytokine concentrations, mainly TNF- $\alpha$, IL- 6 and IL- $1 \beta$, may be responsible for insulin resistance improvement, the favorable effects of diacerein on blood lipids and its liver protecting potential against NASH development.

In agreement with our results several studies confirm the inhibitory effect of diacerein on pro-inflammatory cytokines. Pasin et al found that diacerein inhibits the release of TNF- $\alpha$ and IL- $1 \beta$ and reduced their levels in the peritoneal fluid of rats. ${ }^{9}$

Moore et al reported that the chondroprotective effects of diacerein is mainly explained by a reduction in the concentrations of pro-inflammatory cytokine especially TNF- $\alpha$ and IL- 6 . $^{22}$

Moreover, in accordance with our results, Tobar et al reported that diacerein improves insulin sensitivity, reduces macrophage infiltration and cytokine production in the muscle and liver in an animal model of obesity and type 2 diabetes. ${ }^{23}$ These effects lead to improvement in insulin signaling in the liver accompanied by a reduction in hepatic glucose output and glucose concentrations. However, in contrast with our finding that diacerein administration was accompanied with improvement in lipid profile and reduction in total cholesterol, Tobar et al found insignificant effect of diacerein on lipid profile and this may be due to the relative short duration of diacerein treatment (10 days) compared to our study. ${ }^{23}$ Coincides with our findings, a recent study by Villar et al demonstrated that diacerein as an add-on to metformin improves glycemic control and significantly decreasing fasting blood glucose in diabetic patients. ${ }^{24}$ 
Several studies have suggested that pro-inflammatory cytokines such as TNF- $\alpha$, IL- 6 and IL- $1 \beta$ are involved in the progression of simple steatosis to NASH. TNF- $\alpha$ has a central role in the development of fatty liver and subsequently NASH. Elevated circulating TNF- $\alpha$ levels are associated with obesity and insulin resistance both in animal models and humans. ${ }^{25}$ Moreover, mice genetically deficient in TNF- $\alpha$ receptor I have proved resistant to $\mathrm{NASH}$ induced by different diets, ${ }^{26}$ while treatment of mice with TNF- $\alpha$ antibodies improved hepatic insulin resistance and fatty liver. ${ }^{27}$

IL-6 is one of the first proteins synthesized in acute phase, and plays an important role in the transition from the acute to chronic inflammation. Elevated levels of IL-6 were previously reported in animal models of $\mathrm{NASH}^{28}$ IL-6 expression was found to be increased in the liver of patients with $\mathrm{NASH}$, and was associated with elevation of circulating IL-6 levels, and correlated with disease severity. ${ }^{29}$ Studies of Ota et al support the idea that excessive production of IL-6 versus the defective production of adiponectin may provide a link between insulin resistance and inflammation in $\mathrm{NASH}^{30}$

The IL-1 $\beta$ also plays an important role in the transformation process of hepatic simple steatosis into $\mathrm{NASH}$, Kamari et al found that lack of IL- $1 \alpha$ or IL-1 $\beta$ inhibited the transformation of steatosis into steatohepatitis and liver fibrosis, in hypercholesterolemic mice. $^{31}$ In consistent with our results, Stienstra et al showed that IL-1 $\beta$ promotes liver steatosis and fibrosis. ${ }^{32}$

Among the most investigated adipokines, adiponectin, visfatin and leptin seem to play a prominent role in the pathogenesis and progression of NASH. ${ }^{5}$

Adiponectin is an adipocyte derived cytokine and is considered as an anti-inflammatory adipokine and TNF- $\alpha$ antagonist. It reduces body fat, improves hepatic and peripheral insulin sensitivity, and is inversely associated with body mass index and insulin resistance. In the liver, it prevents lipid accumulation by increasing-oxidation of free fatty acids and/or by decreasing de novo free fatty acids within hepatocytes. Furthermore, adiponectin has a protective role in liver inflammation and fibrosis. Adiponectin knockout mice develop more severe hepatic steatosis when fed with a diet aiming to induce NASH. ${ }^{33}$ $\mathrm{Xu}$ et al also observed a protective effect of adiponectin in fatty liver disease in mice. ${ }^{34}$ Masaki et al found that adiponectin prevents hepatic injury by inhibiting the synthesis and/or release of TNF- $\alpha . .^{35}$

With regard to visfatin, a new adipokine with proinflammatory and metabolic properties, Jamali et al demonstrated the increased probability of NASH presence with decreased serum adiponectin and elevated levels of circulating visfatin, and TNF- $\alpha .{ }^{4}$ In the present research, serum visfatin levels were significantly increased in NASH rats that is in line with previous studies. ${ }^{36,37}$ Likewise, serum visfatin was correlated with systemic insulin resistance and development of metabolic syndrome. ${ }^{37}$ On the other hand, circulating visfatin was significantly decreased in the end stage liver disease presumably due to decreased hepatic production. ${ }^{38}$ Animal studies have proven that leptin, which is mainly produced by adipocytes, directly promotes fibrogenesis as it induces transforming growth factor $\beta$ (TGF- $\beta$ ) ${ }^{5}$ In the present study, HFHC diet induced increased level of circulating leptin. In accordance with our study, Polyzos et al reported that circulating leptin levels were higher in patients with NAFLD than in controls. Higher levels of circulating leptin were associated with increased severity of NAFLD. ${ }^{39}$ Furthermore, Aller et al declared that leptin receptors become resistant to its effect leading to hyperleptinemia which alters insulin signaling and promotes accumulation of intracellular fatty acids in hepatocytes thereby increasing hepatic steatosis and steatohepatitis. $^{40}$

In our study, diacerein was able to increase the level of adiponectin and decrease the level of visfatin in HFHC diet fed rats, but its effect on leptin level was insignificant. The favorable effects of diacerein on adipokines allows us to speculate that these effects are involved in the liver protective role of diacerein against NASH besides its effects on the other pro-inflammatory cytokines.

\section{CONCLUSION}

Administration of diacerein as an anti-inflammatory drug was seen to be useful for preventing NASH in animals fed a HFHC diet. Diacerein attenuated liver inflammation as confirmed by histopathological examination and also improved insulin sensitivity. In addition, it has favorable effects on blood lipid profile. These effects are in part through inhibition of pro-inflammatory cytokines, TNF- $\alpha$, IL-6 and IL-1 $\beta$, and its significant beneficial effects on adipokines especially adiponectin and visfatin. Diacerein may be a therapeutic option for decreasing liver inflammation in NASH, however, further studies are needed in order to evaluate the clinical usefulness of diacerein in patients with NAFLD and NASH.

\section{Acknowledgments}

The Author would like to thanks Prof. Fouad El Debakey (Department of Biochemistry, Faculty of Medicine, Benha University, Egypt) for his assistance in biochemical analysis and Dr. Ghada A. Abd-Elfattah (Department of Pathology, Faculty of Medicine, Benha University, Egypt) for her kind help in the histopathological part of this study

\author{
Funding: No funding sources \\ Conflict of interest: None declared \\ Ethical approval: The study was approved by the \\ Institutional Ethics Committee
}




\section{REFERENCES}

1. Vernon G, Baranova A, Younossi ZM. Systematic review: the epidemiology and natural history of nonalcoholic fatty liver disease and non-alcoholic steatohepatitis in adults. Aliment Pharmacol Ther. 2011;34:274-285.

2. Huang YY, Gusdon AM, Qu S. Nonalcoholic fatty liver disease: molecular pathways and therapeutic strategies. Lipids in Health and Disease. 2013;12:171.

3. Marra F, Tacke F. Roles for chemokines in liver disease. Gastroenterology. 2014;147:577-94.

4. Jamali R, Arj A, Razavizade M, Aarabi MH. Prediction of nonalcoholic fatty liver disease via a novel panel of serum adipokines. Medicine. 2016;95(5):2630.

5. Casoinic F, Sampelean D, Buzoianu AD, Hancu N, Baston D. Serum levels of cytokines and adipokines in patients with non-alcoholic steatohepatitis and type 2 diabetes mellitus. HVM Bioflux. 2016;8(2):77-84.

6. Wang W, Zhao C, Zhou J, Zhen Z, Wang Y, Shen C. Simvastatin ameliorates liver fibrosis via mediating nitric oxide synthase in rats with non-alcoholic steatohepatitis-related liver fibrosis. PLoS One. 2013;8:76538.

7. Zhang W, Wang LW, Wang LK, Li X, Zhang H, Luo LP, et al. Betaine protects against high-fat-diet induced liver injury by inhibition of high-mobility group box 1 and Toll-like receptor 4 expression in rats. Dig Dis Sci. 2013;58:3198-3206.

8. Wouters K, van Gorp PJ, Bieghs V, Gijbels MJ, Duimel H, Lütjohann D, et al Dietary cholesterol, rather than liver steatosis, leads to hepatic inflammation in hyperlipidemic mouse models of nonalcoholic steatohepatitis. Hepatology. 2008;48:474-86.

9. Pasin JS, Ferreira AP, Saraiva AL, Ratzlaff V, Andrighetto R, Tomazetti J, et al. Diacerein decreases TNF-alpha and IL-1beta levels in peritoneal fluid and prevents Baker's yeast-induced fever in young rats. Inflamm Res. 2010;59(3):189-96.

10. Ramos-Zavala MG, González-Ortiz M, MartínezAbundis E, Robles-Cervantes JA, González-López R, Santiago-Hernández NJ. Effect of diacerein on insulin secretion and metabolic control in drug-naive patients with type 2 diabetes: a randomized clinical trial. Diabetes Care. 2011;34(7):1591-4.

11. Pavelka K, Bruye`re O, Cooper C, Kanis JA, Leeb BF, Maheu E, et al. Diacerein: Benefits, Risks and Place in the Management of Osteoarthritis. An Opinion-Based Report from the ESCEO. Drugs Aging. 2016;33:75-85.

12. Jain A, Singh R, Singh S, Singh S. Diacerein protects against iodoacetate-induced osteoarthritis in the femorotibial joints of rats. $\mathrm{J}$ Biomed Res. 2015;29(5):405-13.

13. Trinder P. Determination of blood glucose using an oxidase-peroxidase system with a non-carcinogenic chromogen. J Clin Pathol. 1969;22(2):158-61.
14. Matthews DR, Hosker JP, Rudenski AS, Naylor BA, Treacher DF, Turner RC. Homeostasis model assessment: Insulin resistance and beta-cell function from fasting plasma glucose and insulin concentrations in man. Diabetologia. 1985;28:412-9.

15. Friedewald WT, Levi RI, Fredrickson DS. Estimation of the concentration of low density lipoprotein cholesterol in plasma without use of the ultracentrifuge. Clin Chem. 1972;18(6):499-502.

16. Brunt EM, Janney CG, Bisceglie AMDi, Neuschwander-Tetri BA, Bacon BR. Nonalcoholic steatohepatitis: a proposal for grading and staging the histological lesions. Am J Gastroenterol.1999;94(9):2467-74.

17. McCullough AJ. Epidemiology of the metabolic syndrome in USA. J Dig Dis. 2011;12:333-40.

18. Teratani T, Tomita K, Suzuki T. A high-cholesterol diet exacerbates liver fibrosis in mice via accumulation of free cholesterol in hepatic stellate cells. Gastroenterology. 2012;142:152-64.

19. Lee Y, Sutedja D, Wai C, Dan Y, et al. Randomized controlled pilot study of entoxifylline in patients with non-alcoholic steatohepatitis (NASH). Hepatol Int. 2008;2:196-201.

20. Browning JD, Horton JD. Molecular mediators of hepatic steatosis and liver injury. J Clin Invest. 2004;114:147-52.

21. Gustafson B. Adipose tissue, inflammation and atherosclerosis. J Atheroscler Thromb. 2010;17:33241.

22. Moore AR, Greenslade KJ, Alam CA, Willoughby DA. Effects of diacerhein on granuloma induced cartilage breakdown in the mouse. Osteoarthritis Cartilage. 1998;6(1):19-23.

23. Tobar N, Oliveira AG, Guadagnini D, Bagarolli RA, Rocha GZ, Araujo TG. et al. Diacerhein improves glucose tolerance and insulin sensitivity in mice on a high-fat diet. Endocrinology. 2011;152:4080-93.

24. Villar MM, Martínez-Abundis E, Preciado-Márquez RO, González-Ortiz M. Effect of diacerein as an addon to metformin in patients with type 2 diabetes mellitus and inadequate glycemic control. Arch Endocrinol Metab. 2017;13.

25. Borst SE. The role of TNF-alpha in insulin resistance. Endocrine. 2004;23:177-82.

26. Tomita K, Tamiya G, Ando S, et al. Tumour necrosis factor- $\alpha$ signalling through activation of Kupffer cells plays an essential role in liver fibrosis of nonalcoholic steatohepatitis in mice. Gut. 2006;55(3):415-24.

27. Li Z, Yang S, Lin H, Huang J, Watkins PA, Moser $\mathrm{AB}$, et al. Probiotics and antibodies to TNF inhibit inflammatory activity and improve nonalcoholic fatty liver disease. Hepatology. 2003;37(2):343-50.

28. Mas E, Danjoux M, Garcia V, Carpentier S, Ségui B, Levade T. IL-6 Deficiency Attenuates Murine DietInduced Non-Alcoholic Steatohepatitis. PLoS ONE 2009;4(11):7929.

29. Wieckowska A, Papouchado BG, Li Z, Lopez R, Zein NN, Feldstein AE. Increased hepatic and 
circulating interleukin-6 levels in human nonalcoholic steatohepatitis. Am J Gastroenterol 2008;103(6):1372-79.

30. Ota T, Takamura T, Kurita S, Matsuzawa N, Kita Y, Uno $\mathrm{M}$, Akahori $\mathrm{H}$, et al. Insulin resistance accelerates a dietary rat model of nonalcoholic steatohepatitis. Gastroenterology. 2007;132(1):28293.

31. Kamari Y, Shaish A, Vax E, Shemesh S, Kandel-Kfir M, Arbel Y, et al. Lack of interleukin-1 $\alpha$ or interleukin-1 $\beta$ inhibits transformation of steatosis to steatohepatitis and liver fibrosis in hypercholesterolemic mice. J Hepatol. 2011;55(5):1086-94.

32. Stienstra R, Saudale F, Duval C, Keshtkar S, Groener JE, van Rooijen $\mathrm{N}$, et al. Kupffer cells promote hepatic steatosis via interleukin-1beta-dependent suppression of peroxisome proliferator-activated receptor alpha activity. Hepatology. 2010;51:511-22.

33. Kamada Y, Matsumoto H, Tamura S, Fukushima J, Kiso S, Fukui K, et al. Hypoadiponectinemia accelerates hepatic tumor formation in a nonalcoholic steatohepatitis mouse model. Journal of hepatology. 2007;47(4):556-64.

34. $\mathrm{Xu} \mathrm{A,} \mathrm{Wang} \mathrm{Y,} \mathrm{Keshaw} \mathrm{H}, \mathrm{Xu}$ LY, Lam KSL, Cooper GJS. The fat-derived hormone adiponectin alleviates alcoholic and nonalcoholic fatty liver diseases in mice. $\mathbf{J}$ Clinical Investigation 2003;112(1):91-100.

35. Masaki T, Chiba S, Tatsukawa H, Yasuda T, Noguchi H, Seike M, et al. Adiponectin protects
LPS-induced liver injury through modulation of TNF- $\alpha$ in KK-Ay obese mice. Hepatology. 2004;40(1):177-84.

36. López-Bermejo A, Chico-Julià B, Fernàndez-Balsells M, Recasens M, Esteve E, Casamitjana R, et al. Serum visfatin increases with progressive $\beta$-cell deterioration. Diabetes. 2006;55(10):2871-5.

37. Esteghamati A, Morteza A, Zandieh A, Jafari S, Rezaee M, Nakhjavani M, et al. The value of visfatin in the prediction of metabolic syndrome: a multifactorial analysis. Journal of cardiovascular translational research. 2012;5(4):541-6.

38. de Boer JF, Bahr MJ, Böker KH, Manns MP, Tietge UJ. Plasma levels of PBEF/Nampt/visfatin are decreased in patients with liver cirrhosis. American Journal of Physiology-Gastrointestinal and Liver Physiology. 2009;296(2):196-201.

39. Polyzos SA, Aronis KN, Kountouras J, Raptis DD, Vasiloglou MF, Mantzoros CS. Circulating leptin in non-alcoholic fatty liver disease: a systematic review and meta-analysis. Diabetologia 2016;59(1):30-43.

40. Aller R, Izaola O, Ruiz-Rebollo L, Pacheco D, de Luis DA. Predictive factors of non-alcoholic steatohepatitis: relationship with metabolic syndrome. Nutr Hosp 2015;31(6):2496-502.

Cite this article as: Abd Allah OM. Beneficial effects of diacerein on adipokines and proinflammatory cytokines involved in diet-induced non-alcoholic steatohepatitis in rats. Int J Basic Clin Pharmacol 2017;6:811-20. 